\title{
Skeletally Mature
}

National Cancer Institute

\section{Source}

National Cancer Institute. Skeletally Mature. NCI Thesaurus. Code C156785.

An indication that an individual's growth plates are fused and that bone growth has ceased. 